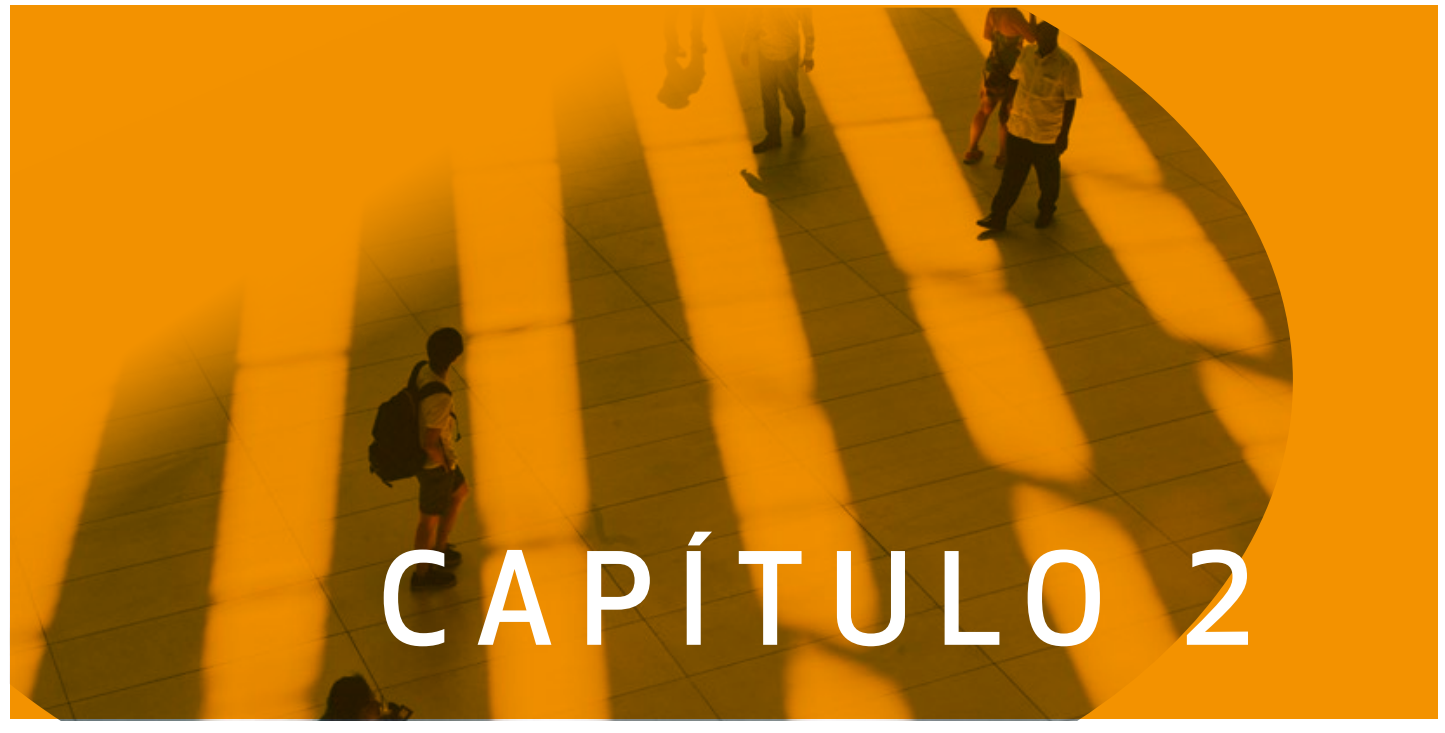





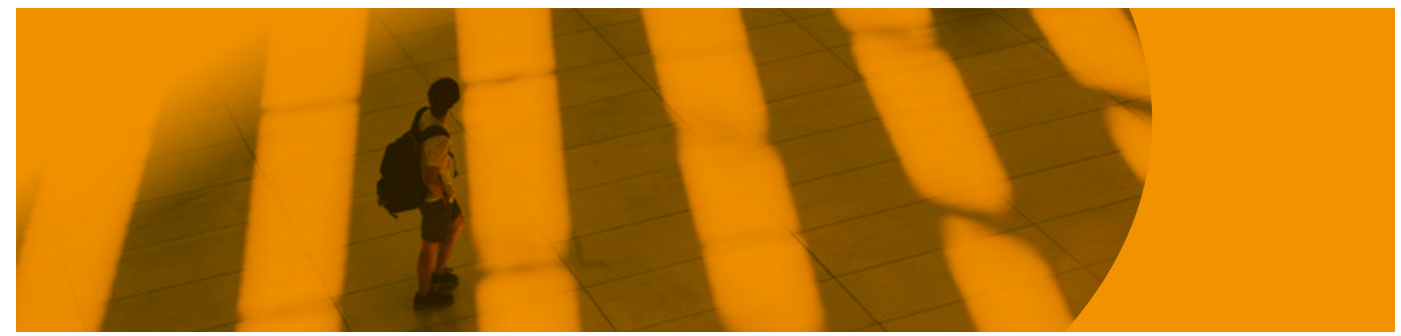

\section{Necesidades de la población, las regiones y los sectores productivos}

\section{Sandra Rocío Mondragón Arévalo}

Doctora en Gestión, Universidad EAN, Colombia. Magister en Dirección y

Administración de Empresas, Universidad Pedagógica y Tecnológica de Colombia.

Especialista en Alta Gerencia, Universidad Militar Nueva Granada, Colombia.

Administradora de Empresas, Universidad Militar Nueva Granada, Colombia. Decana Nacional de la Escuela de Ciencias Administrativas, Contables, Económicas y de Negocios (ECACEN), Universidad Nacional Abierta y a Distancia (UNAD), Colombia. Investigadora Grupo de Investigación Giepe. Correo electrónico: sandra.mondragon@ unad.edu.co

\section{Martha Lucía Fuertes Díaz}

Doctora en Administración Gerencial (C), Universidad Benito Juárez, México. Magíster en Administración con énfasis en Finanzas Corporativas, Universidad ICESI, Colombia. Especialista en Finanzas con concentración en Finanzas Avanzadas, Universidad ICESI, Colombia. Contadora Pública, Universidad Santiago de Cali, Colombia. Docente Universidad Nacional Abierta y a Distancia, UNAD, Colombia. Investigadora principal Grupo de Investigación ilama.

Correo electrónico: martha.fuertes@unad.edu.co

ORCID: http://orcid.org/0000-0001-8468-1867

Google Scholar: https://scholar.google.com.co/citations?user=IP5s- 


\section{Introducción}

El capítulo anterior se centró en el análisis de la importancia de la profesión contable en el contexto nacional e internacional. Se identificaron las políticas públicas que regulan el desempeño de los profesionales y del ejercicio profesional de la contaduría pública y la educación contable superior. Se estableció la importancia del desarrollo de competencias disciplinares en la formación integral del futuro contador, que lo faculta para ejercer ética y competitivamente su función y garantizar así, a la sociedad y al sector empresarial, su competencia profesional y su desempeño ético. Esto lo convierte en un verdadero garante y generador de la confianza pública como coadyuvador para el desarrollo económico de las organizaciones, la sociedad y el país.

El presente capítulo se orienta a la caracterización y establecimiento de las necesidades del tejido empresarial en Colombia, conformado por organizaciones con marcadas diferencias y, por lo tanto, variadas necesidades. Esto depende del sector económico donde se desempeñen, el tipo de empresa, tamaño, y, en fin, múltiples características que requieren del desempeño profesional competente del contador público. El cual se debe adaptar, comprender y aportar al desarrollo, en la búsqueda de crecimiento y permanencia de las organizaciones, así como los beneficios para las regiones y comunidades donde se desempeñan.

\section{Necesidades desde las regiones y sectores productivos}

Considerando que los profesionales de la contaduría pública impactan con su gestión directamente al sector empresarial, se tomó como base para el análisis de las necesidades actuales de los sectores productivos y las regiones, 
el informe emitido por CONFECÁMARAS, ${ }^{3}$ denominado Nacimiento y supervivencia de las empresas en Colombia publicado en septiembre de 2016. Informe que ilustra la dinámica empresarial entre el año 2011 a 2015, y sus implicaciones sobre la estructura productiva del país, sectores económicos y regiones.

Las cifras que presenta el informe son tomadas directamente del Registro Único Empresarial y Social (RUES) a partir de la información empresarial suministrada en la renovación anual de la matrícula mercantil que realizan obligatoriamente todas las empresas del país en las respectivas Cámaras de Comercio.

Para la construcción de los indicadores de la demografía empresarial del informe, CONFECÁMARAs acoge los lineamientos que establece la Oficina de Estadística de la Unión Europea (EUROSTAT) y la Organización para la Cooperación y el Desarrollo Económicos (OCDE), condensada en el manual titulado Eurostat-OCDE Manual on Business Demography Statistics.

De acuerdo con el informe, en el año 2011 había 1.197.573 unidades productivas, de las cuales 280.620 eran sociedades y 916.953 personas naturales. Mientras que para el año 2015 ascendieron a 1.379.284 unidades productivas, con 370.318 sociedades y 1.008.996 personas naturales, como se aprecia en la figura 5.

Durante este período ingresaron 1.033.211 empresas y salieron 991.911, lo que equivale a una tasa de nacimiento promedio del $23,1 \%$ y de salidas de $19,5 \%$, que representa una entrada promedio del 3,6\%. El crecimiento de sociedades es del $7,3 \%$ anual y de personas naturales del $2,4 \%$ anual.

3 La Confederación Colombiana de Cámaras de Comercio (ConfeCÁmARAs), es una entidad privada, sin ánimo de lucro, que agremia y representa las 57 entidades del sector que existen en Colombia. Como organismo de carácter nacional, coordina y brinda asistencia para el desarrollo de las funciones de las Cámaras de Comercio colombianas; en las cuales las empresas colombianas registran o renuevan anualmente su registro mercantil. 


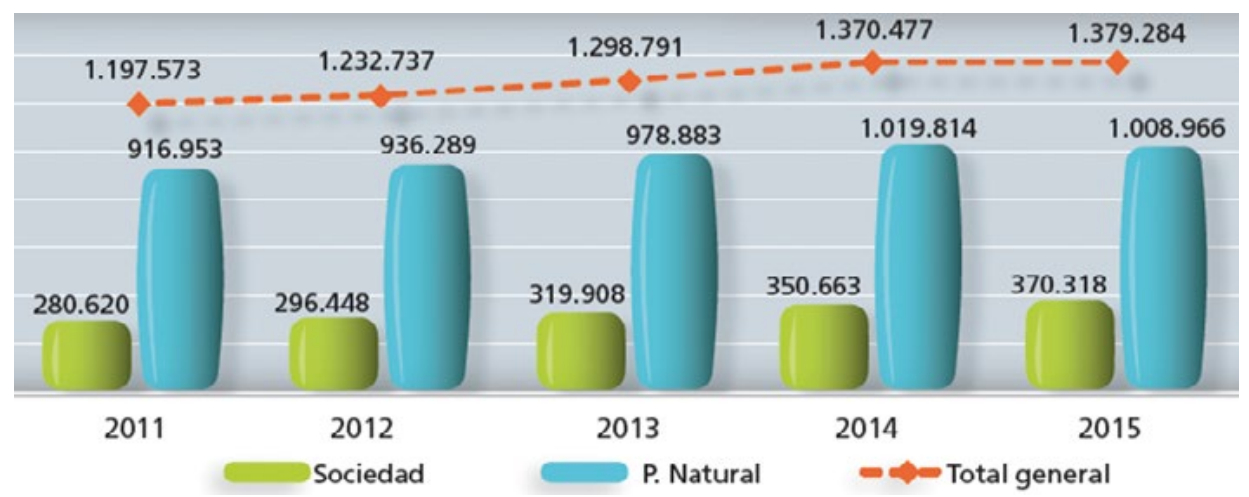

Figura 5: Evolución del stock de empresas colombianas, 2011-2015.

Fuente: Informe CONFECÁmARAS. Septiembre de 2016, a partir de datos del RUES

El informe de CONFECÁMARAS establece que, para los nuevos emprendimientos, la tasa de supervivencia es del $29,7 \%$. Esto equivale a decir que el $70 \%$ de los nuevos emprendimientos fracasan en los primeros cinco años de vida.

La tasa de supervivencia en Colombia es muy baja, al compararla con la de países de la OCDE, como Francia con el 52,7\%, Italia con el 48,3\%, España con el $39,9 \%$ y Reino Unido con el $37,5 \%$.

Este comportamiento en la tasa de supervivencia para las empresas colombianas, se explica con el comportamiento de las empresas creadas por personas naturales en las cuales la tasa de supervivencia es apenas del 25,2\%, mientras que la tasa de supervivencia de las sociedades es del $42,8 \%$.

Otro factor que incide en la tasa de supervivencia es el "tamaño", pues las grandes empresas tienen una tasa del $74,1 \%$, las medianas empresas el $68 \%$, las pequeñas empresas el $60 \%$, pero para las microempresas la tasa de supervivencia es apenas del 29,1\%. En el plano regional, se observa un comportamiento similar al promedio nacional y por departamentos. 
De acuerdo con la actividad que desarrollan las empresas, de las 1.379.284 unidades productivas en Colombia, el mayor grupo se dedica al sector comercio con $42,1 \%$, el 39,6 \% a actividades de servicios, el 13,1 \% a la industria y el 5,4 \% a actividades del sector construcción. Es importante señalar que en este estudio no se incluye la actividad agrícola. De acuerdo con el tamaño, el 92,1\% son microempresas, el 7,5\% son Pymes y el 0,5\% corresponde a las grandes empresas, como se aprecia en la figura 6.

\begin{tabular}{|c|c|c|c|}
\hline Tamaño & $\begin{array}{c}\text { Total de empresas } \\
2015 \\
\end{array}$ & $\begin{array}{c}\text { Estructura porcentual } \\
2015 \\
\end{array}$ & $\begin{array}{c}\text { Densidad empresarial } \\
\text { (Empresa/mil hab.) }\end{array}$ \\
\hline Total & 1.379 .284 & 100 & 28,6 \\
\hline Mloroempresa & 1.273 .017 & 92,1 & 26,4 \\
\hline Pequeña & 79.926 & 5,9 & 1,7 \\
\hline Medlana & 19.980 & 1,5 & 0,4 \\
\hline Grande & 6.361 & 0,5 & 0,1 \\
\hline
\end{tabular}

Figura 6. Distribución de empresas por tamaño, 2015.

Fuente: Informe CONFECÁMARAS a septiembre de 2016, a partir de datos del RUES

En la figura 7 se ilustra la tendencia en tamaño de las empresas de acuerdo con el sector económico en el que se desempeñan.

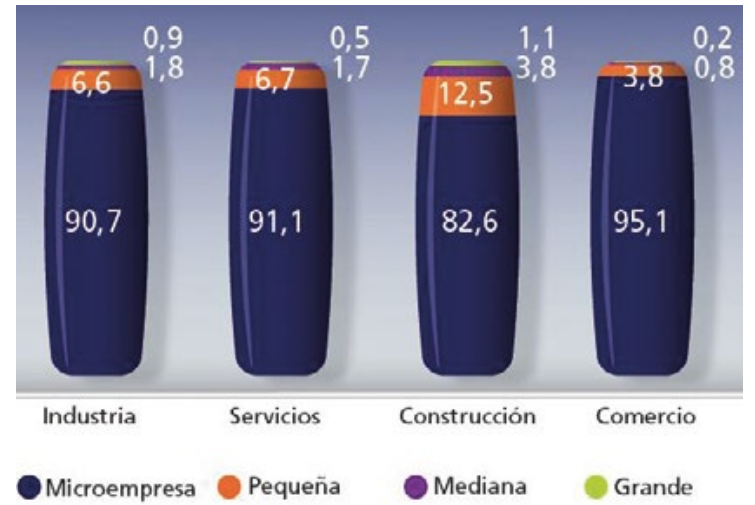

Figura 7. Distribución de empresas por sector económico y tamaño, 2015.

Fuente: Informe Confecámaras a septiembre de 2016, a partir de datos del RUES 
En la figura 8 se aprecia la distribución empresarial por departamento y por actividad en el país, se evidencia la alta diversidad empresarial por sector productivo y su dinámica empresarial.
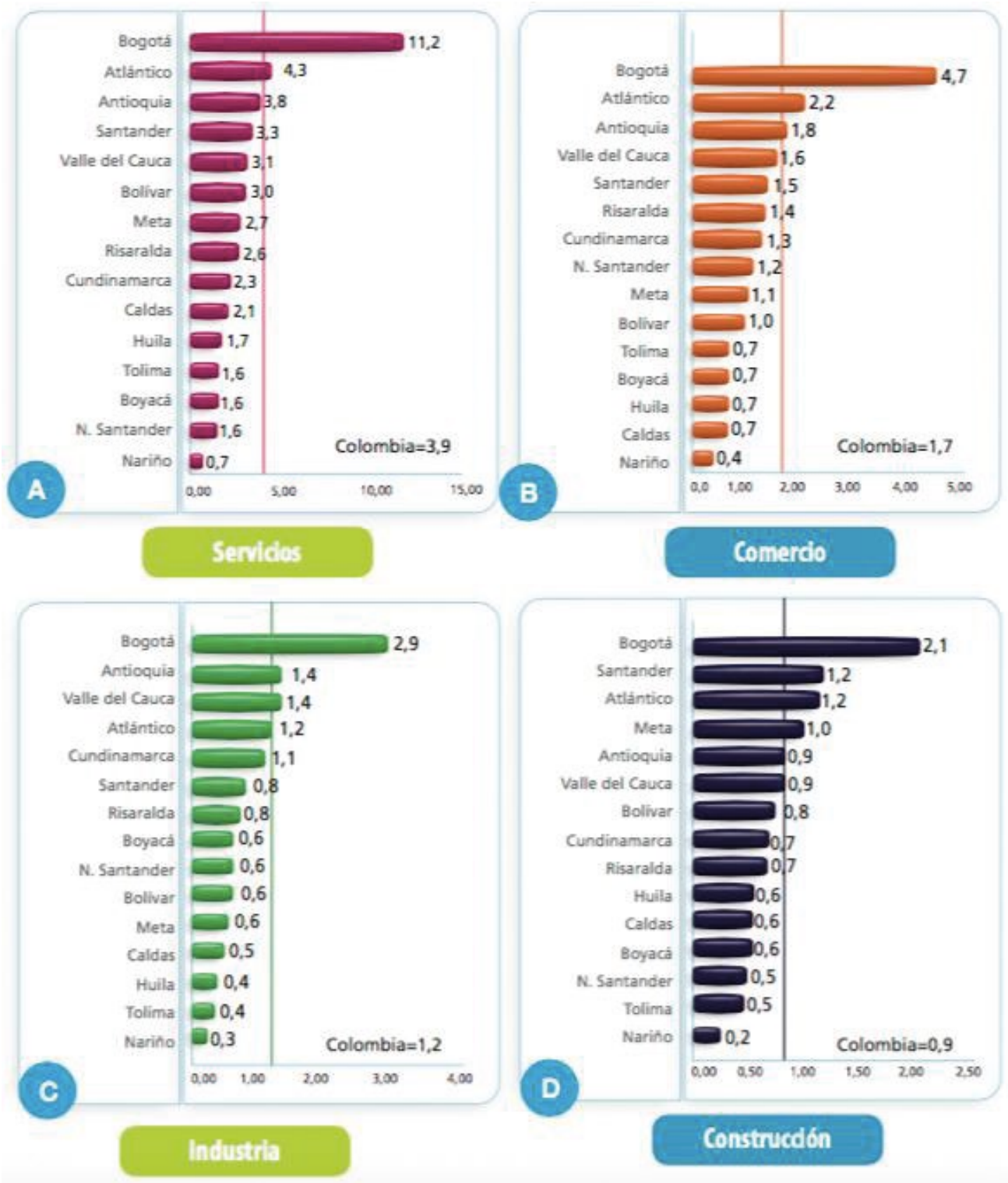

Figura 8. Densidad empresarial por sector económico, 2015.

Fuente: Informe CONFECÁMARAS a septiembre de 2016, a partir de datos del RUES. 
El informe evidencia mayor concentración de las empresas en las regiones con mayor desarrollo económico y densidad poblacional, donde la tasa de concentración es 95,4 \%. Así, la región de Bogotá y Cundinamarca cuentan con 529.762 empresas (38,4 \%), Antioquia y Eje Cafetero con 241.032 empresas $(17,5 \%)$, Santander, Norte de Santander y en general la región oriental con 192.381 empresas (13,9 \%), la región Pacífico y especialmente el Valle del Cauca con $177.572(12,9 \%)$.

Según el informe, y como se aprecia en la figura 8, los departamentos del país se especializan en actividades económicas que guardan relación con las iniciativas clúster en sus regiones: en Antioquia con textil-confecciones, Bogotá con productos farmacéuticos y productos cinematográficos, Bolívar en transporte acuático, Magdalena y Quindío en alojamiento y actividades de agencias de viajes, Santander con productos de refinación de petróleo y Tolima en actividades recreativas, servicios de paisajismo y alojamiento y la construcción en las principales ciudades del país.

Según el último informe sobre la dinámica empresarial en Colombia, presentado por CONFECÁMARAS en 2017. Se reporta que en el año 2016 se crearon 299.632 unidades económicas, de las cuales 76.794 corresponden a sociedades y 222.838 a personas naturales, que equivale al 15,8\% del crecimiento.

El sector agrícola, de acuerdo con los informes estadísticos de la Sociedad de Agricultores de Colombia4 (SAC), para el año 2016 creció el 0,5\% respecto del año anterior, mientras la economía colombiana lo hizo al 2,0\%. Se resalta el crecimiento en la producción de los cereales con el 17,6\% donde sobresale el arroz con un incremento en producción de $27 \%$, el maíz amarillo tecnificado creció 7,5\%, mientras el blanco tecnificado lo hizo en 5,1\%, la actividad pecuaria la producción creció o,9 \%.

4 Sociedad de Agricultores de Colombia (SAC), es la máxima asociación gremial agropecuaria de carácter nacional, integrada principalmente por los gremios de productores agropecuarios, agricultores, avicultores, porcicultores, ganaderos, silvicultores, forestales, pesqueros, acuícolas, profesionales afines, los gremios agropecuarios que los representan, y personas jurídicas del mismo carácter, los gremios no agropecuarios, y las empresas agropecuarias, agroindustriales y de bienes y servicios para el agro. 


\section{Necesidades de los empresarios del país respecto del desempeño de la función contable}

Contar con la percepción de lo que demandan las organizaciones respecto de la función que desempeña el contador público, que coadyuve a su desarrollo, crecimiento y permanencia es fundamental al momento de proponer las competencias a desarrollar desde la educación superior. Igualmente, en lo relacionado a su aporte en el proceso de desarrollo del currículo, orientado a la formación de los futuros profesionales de esta disciplina que respondan pertinentemente a las necesidades del tejido empresarial.

Para ello, se realizó una investigación de percepción de los empresarios del país respecto de las necesidades de la función que desempeña el contador público para el tejido empresarial.

En esta investigación se propuso y aplicaron encuestas a 61 empresarios de las diferentes regiones del país. Fueron realizadas por la Escuela de Ciencias Administrativas, Contables, Económicas y de Negocios de la UNAD y el Grupo de Investigación ILAMA, entre los meses de septiembre a noviembre del año 2016.

La investigación se orientó a la identificación de las necesidades del sector empresarial respecto de la profesión de la contaduría pública y del profesional que la ejerce. Lo anterior para reconocer las necesidades del tejido empresarial del país, que se desempeña en el actual entorno caracterizado por altos estándares en competitividad y por la globalización de los negocios.

En la figura 9 se aprecia la participación de empresarios de los diferentes sectores de la economía; con el $34 \%$ del sector comercial, $33 \%$ del sector servicios, $26 \%$ del sector industrial y $6 \%$ del sector agropecuario. 


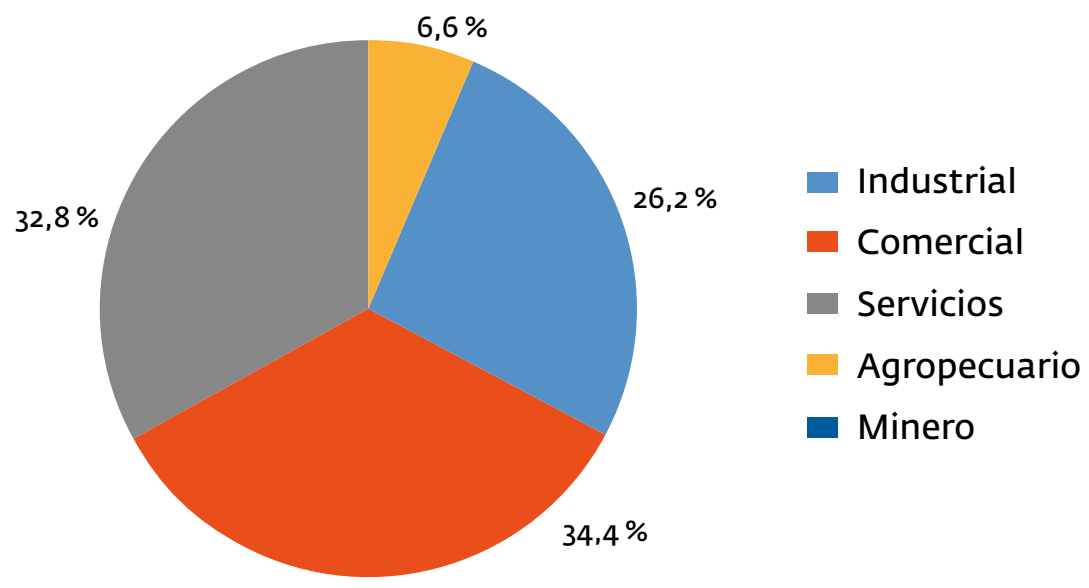

Figura 9. Caracterización empresarial.

Fuente: elaboración propia

Para establecer el tamaño de las empresas participantes, se tomó como base el número de trabajadores vinculados, donde el 36,1\% de las empresas tienen entre 11 y 50 trabajadores, el $28 \%$ tiene menos de 10 trabajadores, el $26 \%$ tienen entre 51 y 200 trabajadores y el 9,8\% tienen más de 200 trabajadores.

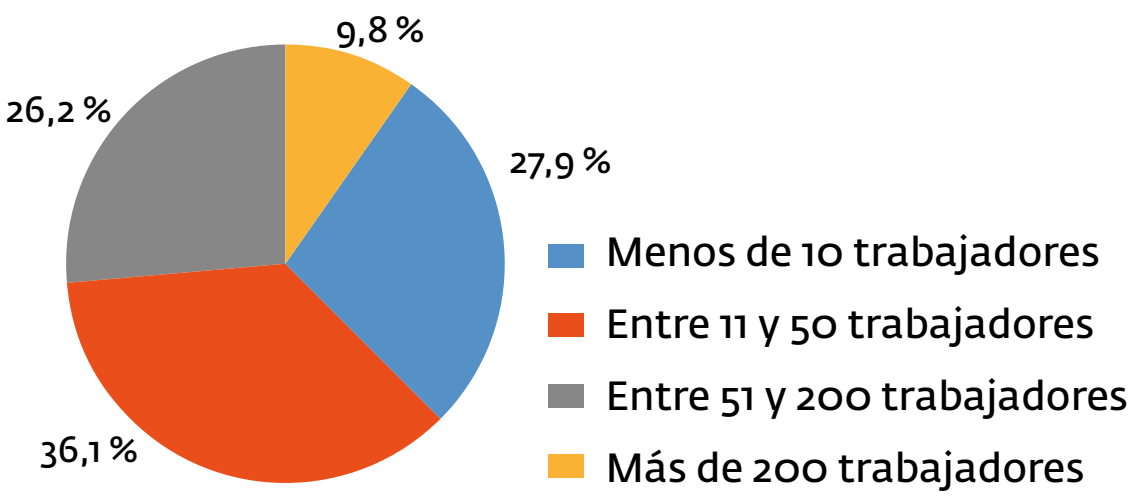

Figura 10. Caracterización empresarial por número de trabajadores.

Fuente: elaboración propia

Se logró establecer que los profesionales de la contaduría pública, además de estar vinculados especialmente en el área contable y financiera de las empre- 
sas, se desempeñan también en las áreas de producción, talento humano, gerencia e incluso mercadeo.

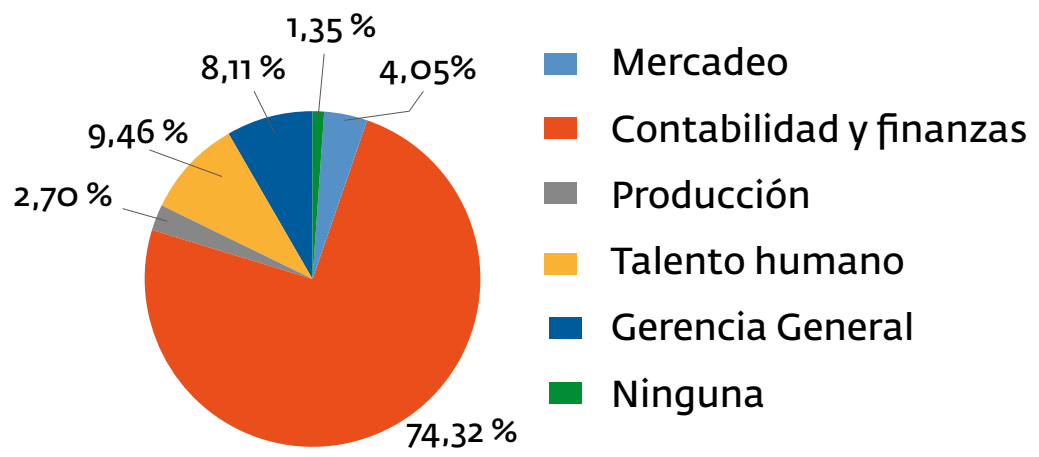

Figura 11. Funciones de desempeño de los contadores públicos.

Fuente: elaboración propia

En el campo disciplinar, las empresas vinculan contadores públicos especialmente para el área contable con el $24 \%$, el $16 \%$ para el área impuestos, el $14 \%$ en revisoría fiscal,y el $12 \%$ para el área financiera.

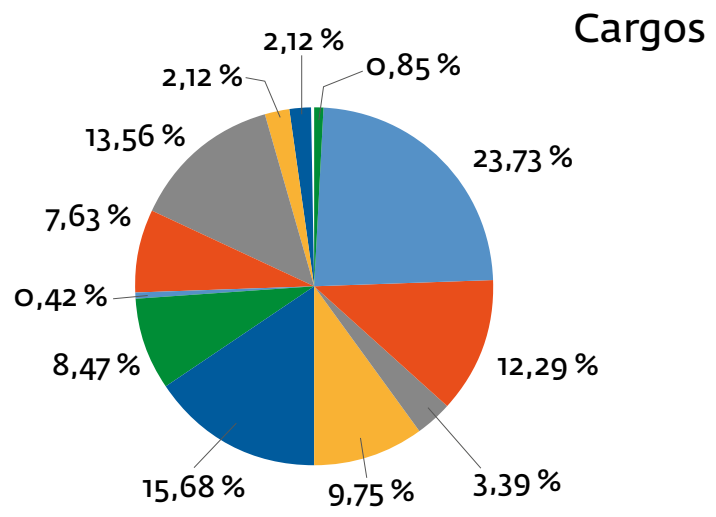

Contabilidad

- Finanzas

- Tesorería

Presupuestos

Impuestos

Figura 12. Principales cargos que desempeñan los contadores públicos.

Fuente: elaboración propia

Según el estudio realizado, sobre las motivaciones para la vinculación de los contadores públicos en las empresas, el 22 \% los requieren para dar fe pública de la información financiera, el 19,81 \% para liquidar y presentar las declaraciones 
tributarias, el $19 \%$ para sistematizar la información financiera, el $17 \%$ para cumplir con las exigencias legales, como aspectos más sobresalientes, entre otros.

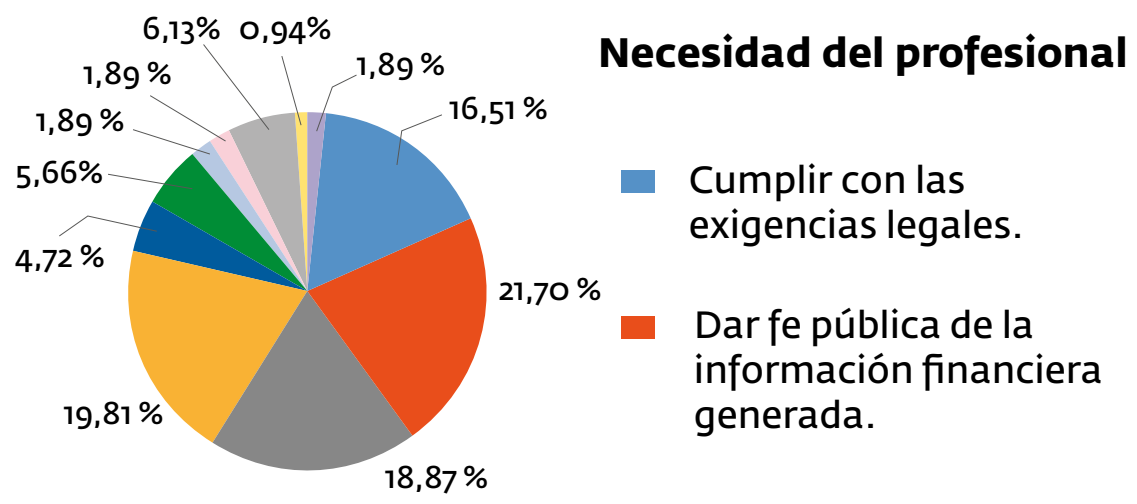

Figura 13. Necesidades en la gestión profesional del contador público.

Fuente: elaboración propia

Sobre las cualidades necesarias para el eficiente desempeño del contador público, resaltaron la ética y la competencia disciplinar, cada una con $17 \%$, la responsabilidad con $16 \%$ y la organización con $14 \%$, entre otros.

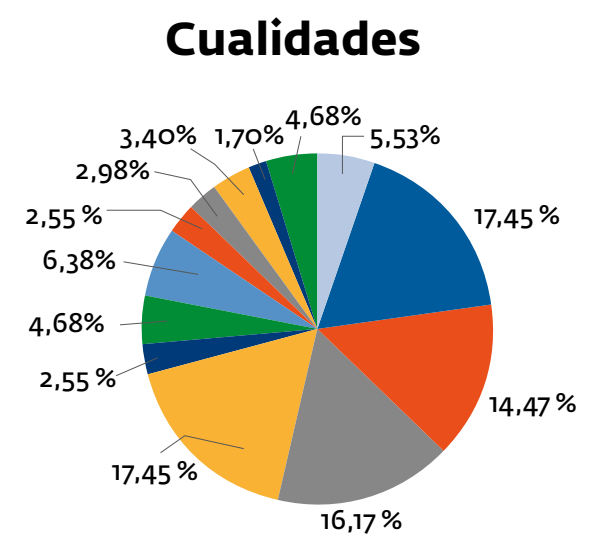

Competente

Organizado

Responsable

- Ético

- Empatía

- Líder

- Trabajo en equipo

- Habilidad para el manejo de la tecnología

- Investigador

- Capacidad de comunicación

- Dominio de segunda lengua

Visión global y prospectiva para el desarrollo de las organizaciónes

Figura 14. Cualidades del contador público.

Fuente: elaboración propia 
De acuerdo con las necesidades actuales del sector empresarial, las capacidades que deben lograr los profesionales de la contaduría pública son, en $28 \%$ desarrollo profesional ético, transparente y socialmente responsable, el 21,39 \% señala la importancia del aporte para la gestión y a la activa toma de decisiones en las organizaciones, el 15,51 \% debe enfocarse al impacto regional y local mediante el aporte de su saber profesional aplicado eficientemente en un contexto globalizado.

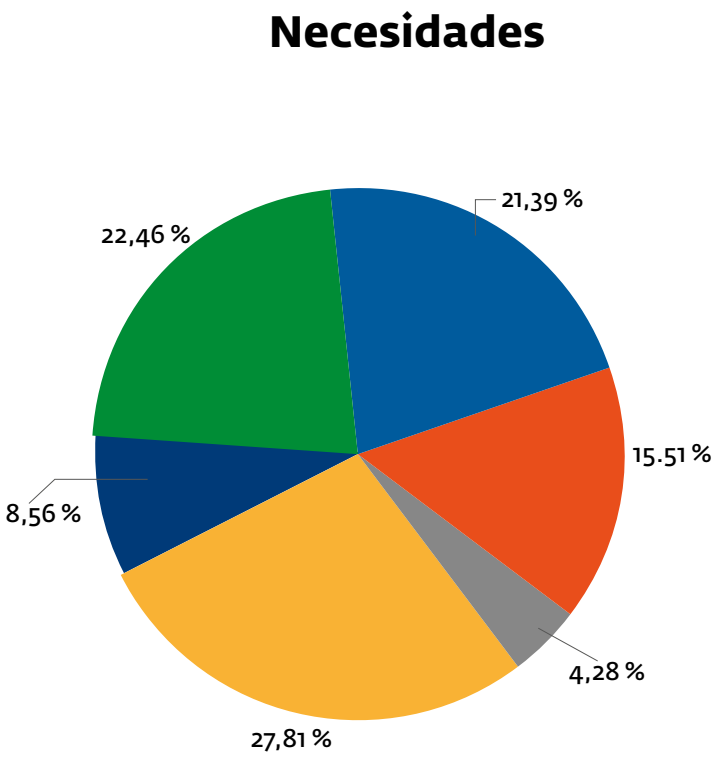

Impactar la sociedad mediante el desempeño de un profesional que aporte a la gestión y a la activa toma de decisiones en las organizaciones

Impactar el desarrollo regional y local mediante el aporte de su saber profesional aplicado eficientemente en un contexto globalizado.

Orientar esfuerzos para el cuidado del medio ambiente desde su saber profesional, como aporte al desarrollo regional y local

Aportar al desarrollo del sector empresarial de manera étca, transparente y socialmente responsable.

- Proponer innovaciones disciplinares organizacionales y sociales.

Enfrentar el reto de la actualización permanente del saber propio de su profesión, tanto en el ámbito local como global

Figura 15. Capacidades del contador público.

Fuente: elaboración propia

De acuerdo con las necesidades actuales del sector empresarial, el profesional de contaduría pública, del presente y para el futuro, requiere para su formación complementaria, en un $29 \%$ capacidad para aportar activamente en la gestión de las organizaciones, en $19 \%$ capacidad para aportar al proceso de toma de decisiones organizacionales, $19 \%$ capacidad para brindar apoyo en gestión de las organizaciones, 18 \% capacidad para actuar en multicontextos sociales, or- 
ganizacionales y culturales, y el $13 \%$ resaltan el dominio de un segundo idioma para la comunicación asertiva en el actual contexto globalizado.

\section{Profesional de hoy y el futuro}

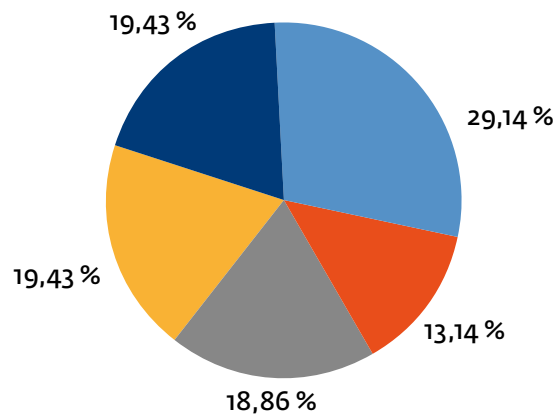

Capacidad para aportar activamente en la gestión de las organizaciones.

Dominio de una segunda lengua para la comunicación asertiva en el conterto globalizado.

Capacidad para actuar en multiconte itos: sociales, culturales y organizaciones.

- Capacidad para brindar apoyo en gestión de las organizaciones.

- Capacidad para la toma de decisiones organizacionales.

Figura 16. Requerimientos para la formación integral del contador público.

Fuente: elaboración propia

Las recomendaciones generadas a partir de los resultados del estudio realizado, para ser consideradas en el diseño curricular de nuevos programas de contaduría pública, se resumen en los siguientes postulados:

- Formación de profesionales de la contaduría pública competentes en lo disciplinar, en consonancia con las Normas Internacionales de Información Financiera y de Aseguramiento, exigibles en el momento actual, tanto desde lo reglamentario como para el aporte al logro de mayores estándares de competitividad del tejido empresarial.

- La formación integral del futuro contador público con un enfoque global, que aporte en la gestión de las organizaciones y pueda desarrollarse en multicontextos sociales y culturales, tanto en el ámbito local como global.

- Formación profesional con fundamento ético, transparente, socialmente responsable y sensible con los problemas sociales y organizacionales, que aporte mediante la investigación soluciones creativas e innovadoras en el proceso de gestión en las organizaciones. 


\section{Necesidades que enfrenta el tejido empresarial colombiano}

De acuerdo con el Ministerio de Comercio, Industria y Turismo (MINCIT), ${ }^{5}$ durante la última década, Colombia ha venido desarrollando una política de inserción internacional mediante la suscripción de tratados de libre comercio, como estrategia comercial que busca abrir y consolidar mercados en el contexto global para la inserción competitiva de las empresas, como se aprecia en la figura 17, lo que se constituye en un reto y una necesidad para el tejido empresarial del país.

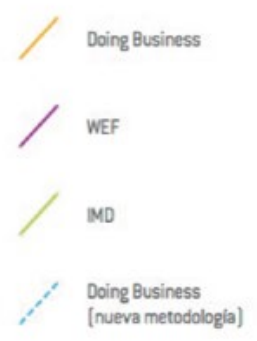

Fuente: WEF, Banco Mundial e IMD.

Cálculos: Consejo Privado de Competitividad.

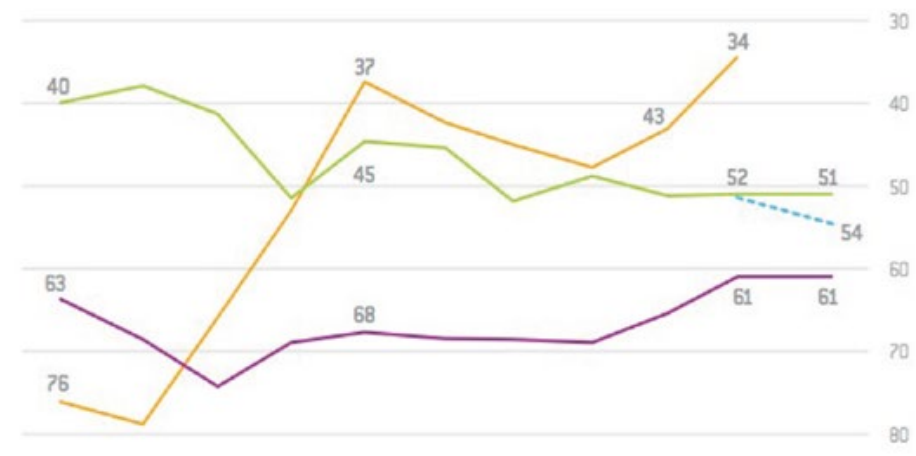

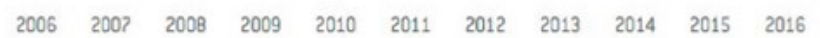

Figura 17. Tratados de libre comercio vigentes de Colombia con el Mundo, 2017. Fuente: WEF, Banco Mundial e IMD

La experiencia muestra que los países que más han logrado desarrollarse en los últimos años son aquellos que se han incorporado exitosamente al comercio internacional, ampliando de esta manera el tamaño del mercado para sus empresas.

5 El Ministerio de Comercio, Industria y Turismo (MINCIT), apoya la actividad empresarial, productora de bienes, servicios y tecnología, así como la gestión turística de las regiones del país para mejorar su competitividad y su sostenibilidad e incentivar la generación de mayor valor agregado. 

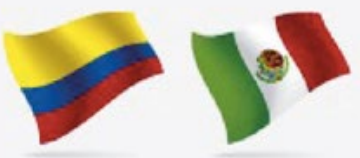

TLC Colombia - México

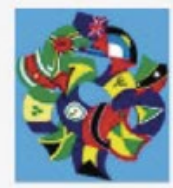

CARICOM

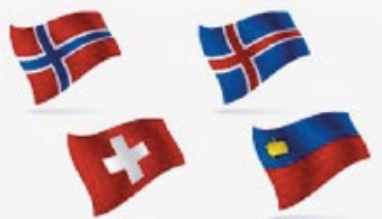

EFTA

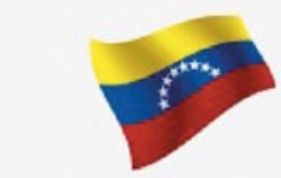

Acuerdo de alcance Parcial con Venezuela

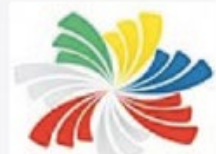

Alianza del Pacífico

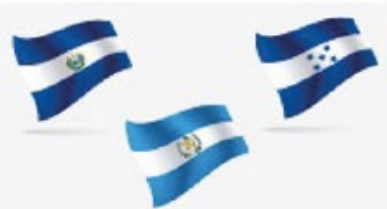

El Salvador, Guatemala y Honduras

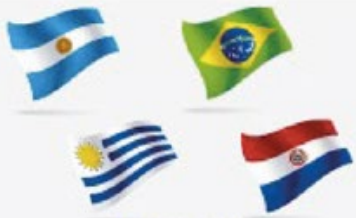

MERCOSUR

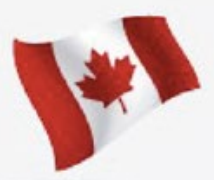

Canadá

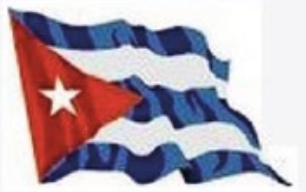

Cuba

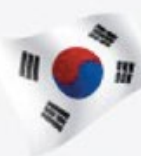

Corea

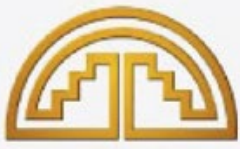

CAN

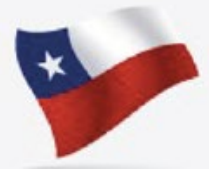

Chile

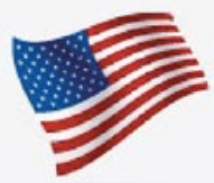

Estados Unidos

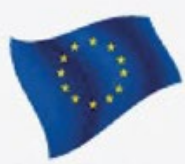

Unión Europea

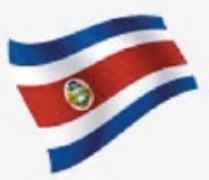

Costa Rica

Figura 18. Tratados vigentes de libre comercio de Colombia con el mundo. Fuente: Ministerio de Comercio, Industria y Turismo, 2017.

En ese sentido, según el MINCIT, a mayo de 2017 Colombia tiene 17 acuerdos internacionales vigentes, uno en proceso de ratificación y tres en proceso de negociación, que se presentan en la figura 18. 
El MINCIT señala que la política nacional, orientada a la globalización del comercio mediante el desarrollo de los tratados internacionales, ha comenzado a dar frutos a partir del desarrollo y generación de impactos hacia las regiones, las cuales se han articulado en este proceso, algunas con mayores avances frente a otras.

Este contexto de desarrollo mercantil globalizado, soportado en el avance de mayores tratados internacionales, pretende motivar e incentivar el desarrollo del tejido empresarial para que traspase exitosamente las fronteras con su actividad mercantil.

En este propósito y orientación de desarrollo competitivo de las organizaciones, es fundamental el apoyo de los profesionales de la contaduría pública que, desde su formación profesional integral, deben desarrollar competencias para aportar al tejido empresarial colombiano en el logro de este propósito.

\section{Necesidades de desarrollo profesional del contador público en Colombia}

La Junta Central de Contadores (JCC), como órgano rector de la profesión de la contaduría pública en Colombia, que desarrolla su labor misional de registro, inspección y vigilancia de los contadores públicos y actúa como Tribunal Disciplinario para garantizar el correcto ejercicio de la profesión contable y la ética profesional, informa que, al año 2016, Colombia contaba con 230.246 contadores públicos con tarjeta profesional vigente.

Al contrastar el número de contadores públicos respecto del número de empresas en Colombia, se puede apreciar que existe una importante oportunidad de desarrollo laboral. Dado que 1.678.916 empresas, que requieren de este tipo de profesionales, se enfrentan a la oferta de 230.246 contadores públicos en el país, al año 2016.

Es importante considerar que las grandes empresas que representan el 0,5\% del total de unidades económicas, demandan de varios profesionales de 
la contaduría pública para liderar las funciones de contador, revisor fiscal, director financiero, auditor, control interno, director de impuestos, contralor, director de presupuestos, tesorería, entre otras.

Por su parte, para las pequeñas y medianas empresas, que representan el 7,4 \% del total de unidades económicas del país, se cuenta con la oportunidad de brindarles apoyo profesional para aportar en su crecimiento sostenido y hacer frente a las obligaciones legales en materia fiscal, de normas internacionales y retos derivados de la competitividad global que enfrentan.

Para las microempresas que se constituyen en la mayor base empresarial del país, con una participación del $92,1 \%$ al año 2015, los profesionales de la contaduría pública enfrentan el reto de aportar significativamente para disminuir la cifra de mortalidad establecida en $70 \%$.

Por su parte, el Observatorio Laboral señala el número de graduados de programas de contaduría pública, en los últimos catorce años, del 2001 al 2015, el cual asciende a 148.129 contadores públicos. Estos hacen parte de los 230.246 contadores públicos que cuentan en Colombia con tarjeta profesional vigente al año 2016, y asumen la responsabilidad de apoyar al tejido empresarial colombiano conformado por 1.678 .916 empresas.

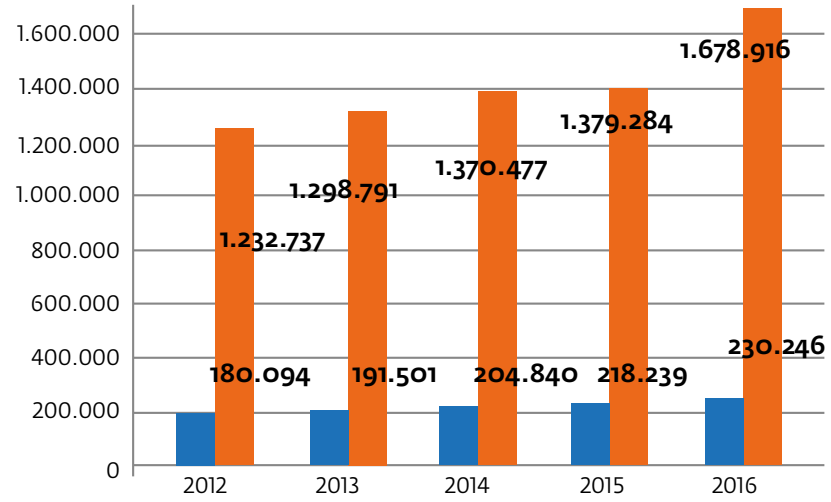

Contadores Públicos

- Total empresas

Figura 19. Empresas Vs Contadores Públicos en Colombia, 2012 a 2016.

Fuente: elaboración propia a partir del Informe CONFECÁMARAS 2017, datos del RUES y Junta Central de Contadores 2016 
Finalmente, y de acuerdo con los análisis realizados, es importante afirmar que las empresas constituyen un número mucho más amplio respecto del número de contadores públicos en Colombia al año 2016. De acuerdo con la tasa de crecimiento de los últimos cinco años, mientras las unidades económicas constituidas como sociedades crecen en promedio anual al 7,3\%, las unidades económicas constituidas como personas naturales lo hacen a la tasa del $2,4 \%$, en comparación con la tasa de crecimiento de nuevos contadores públicos del $5,96 \%$. Lo anterior evidencia la necesidad de potenciar la formación de nuevos profesionales de la contaduría pública que respondan eficientemente a los retos y necesidades que enfrenta el sector empresarial del país y su proyección a futuro. Esto se puede lograr con presencia de programas de contaduría pública en todas las regiones del país, para constituir una base que brinde aporte significativo en la solución de esta problemática.

\section{Necesidades de la comunidad en educación profesional contable}

Para establecer las necesidades de formación profesional en contaduría pública que demanda la comunidad del país, la Escuela de Ciencias Adminsitrativas, Contables, Económicas y de Negocios de la UNAD y el Grupo de Investigación ILAMA, realizaron un estudio de factibilidad de mercado entre los meses de septiembre a noviembre de 2016.

La población seleccionada estableció los estudiantes de educación secundaria, grados 10 y 11, matriculados en instituciones educativas del sector oficial y privado del país, y egresados del SENA de programas de tecnología relacionados con el campo de conocimiento de las ciencias administrativas y económicas. La muestra representativa calculada con base en el número de egresados de la educación media en el país, margen de error del $5 \%$, nivel de confiabilidad del $95 \%$, se estableció en 559 personas. 
Como instrumento de recolección de información se seleccionó la encuesta, que se aplicó en las diferentes regiones del territorio nacional a partir de la infraestructura de la UNAD, con presencia en todas las regiones del país. Distribución que se aprecia en la figura 20.

Tabla 9. Aplicación de encuestas en las regiones del país.

\begin{tabular}{|c|c|c|}
\hline 1. Zona Centro Bogotá Cundinamarca - Nodo: Bogotá D.C. & 77 & $14 \%$ \\
\hline 2. Zona Centro Sur - Nodo: Palmira & 161 & $29 \%$ \\
\hline 3. Zona Sur - Nodo: Ibagué & 109 & $19 \%$ \\
\hline 4. Zona Caribe - Nodo: Barranquilla & 31 & $6 \%$ \\
\hline 5. Zona Caribe - Nodo: Medellín & 51 & $9 \%$ \\
\hline 6. Zona Centro Boyacá - Nodo: Tunja & 62 & $11 \%$ \\
\hline 7. Zona Amazonía Orinoquía - Nodo: Acacias & 68 & $12 \%$ \\
\hline TOTAL & 559 & $100 \%$ \\
\hline
\end{tabular}

Fuente: elaboración propia

Sin embargo, durante el desarrollo de la encuesta se aplicaron 580 encuestas. De los resultados obtenidos se resaltan los aspectos - que se detallan a continuación-como los más representativos para la investigación.

Del total de encuestados, 343, equivalente al $59 \%$, respondieron que su nivel de formación alcanzada es de bachiller, quienes resaltaron la falta de oportunidades por los elevados costos de las universidades en Colombia, y cómo esta situación dificulta su acceso a la educación superior.

Del total de encuestados, el $53 \%$, con 309 encuestados, respondieron que en el momento no están cursando estudios a nivel técnico o tecnológico. Mientras 250 , equivalente al $43 \%$, respondieron que actualmente están cursando una carrera de nivel técnico o tecnológico, principalmente por la falta de oportunidades para acceder a una educación profesional, especialmente por el costo que implica. 
Del total de encuestados, 377 respondieron que conocen la carrera de contaduría pública, lo que equivale al $65 \%$. Complementariamente, 369 de los encuestados, equivalente al $64 \%$, reconocen la importancia de la contaduría pública en la generación de la información financiera de las organizaciones. Del total de encuestados, 253 , equivalente al $44 \%$, señalaron su importancia para el análisis de la situación financiera presente y futura de las empresas. En menor proporción, 170 de los encuestados, equivalente al $20 \%$, resaltaron su aporte en el manejo de la política fiscal de las empresas.

Sobre las cualidades que debe aplicar el contador público en su desempeño profesional, 267 encuestados, equivalente al $46 \%$, resaltaron la ética y la responsabilidad social; 135 encuestados, equivalente al $23 \%$, resaltaron el desarrollo de la capacidad de análisis. En menor proporción señalaron aspectos como conocimientos básicos en matemáticas, disciplina, orden y puntualidad.

Sobre la percepción de oportunidades que brinda estudiar contaduría pública, resaltaron mayores oportunidades de trabajo, mejoramiento de los ingresos y oportunidad de trabajar independiente.

Sobre la metodología de estudio virtual, 280 , equivalentes al $48 \%$, conocen o han desarrollado algún tipo de estudio en esta metodología. Resaltaron como cualidades de esta metodología la flexibilidad de horarios de estudio, capacidad de planear el tiempo de estudio, acceso a zonas rurales donde la educación tradicional no llega, el uso de la tecnología, entre otras.

Del total de encuestados, 314, equivalente al $51 \%$, conocen la UNAD y resaltaron principalmente el uso intensivo de la tecnología en la metodología de estudio virtual. También, 271 encuestados, equivalente al $47 \%$, estarían dispuestos a matricularse en un programa de contaduría pública si es ofrecido por la UNAD.

Finalmente, es importante señalar que el 79 \% de la población encuestada estaría dispuesta a matricularse en un programa de contaduría pública en metodología virtual, gracias a la cobertura nacional. 
Los resultados obtenidos en la investigación realizada permiten establecer la positiva aceptación de la población colombiana respecto de los programas de contaduría pública por la amplias alternativas de desempeño profesional que connota. La positiva aceptación de este programa en metodología virtual tiene un gran impacto social por su cobertura educativa nacional, esto gracias a la cobertura en varias zonas del país, especialmente en las regiones apartadas, donde la educación tradicional no hace presencia. Sumado al aporte y mejoría en la calidad de vida de la población, a partir del bienestar económico y el eficiente manejo del tiempo, que permite.

\section{Conclusiones}

De acuerdo con los análisis realizados, en las múltiples dimensiones se aprecia la diversidad de la actividad económica del país en sus diferentes sectores. Las organizaciones se constituyen en el centro del desarrollo económico y aportan al bienestar social del país, y esto requiere del aporte de los profesionales de la contaduría pública para su desarrollo.

La diversidad empresarial se aprecia en las organizaciones, la cuales pueden ser públicas o privadas, con o sin ánimo de lucro, grandes, medianas o pequeñas, sociedades o personas naturales, de todos los sectores de la economía, bien sea industrial, comercial, servicios, agropecuario, construcción o servicios financieros. Estas empresas, en el actual contexto de desarrollo del país, se ven enfrentadas a la competencia local y global, exigencias en materia legal y fiscal en constante cambio como se evidencia en las reformas tributarias y, sobre todo, en el reto para las organizaciones de generar sus informes financieros con base en los estándares internacionales de Información Financiera (NıIF), como aspecto fundamental en el avance para el logro de mayores estándares de competitividad global. Esto hace que la profesión de la contaduría pública asuma un rol protagónico en este escenario diverso.

Estas exigencias que enfrentan en el día a día todas las organizaciones del país, las cuales se desempeñan desde sus propias regiones, pero con afectaciones 
competitivas globales y los retos generados a partir de los cambios coyunturales que en materia contable se dan por la convergencia a los estándares internacionales para la gestión de la información financiera en las organizaciones. Este cambio está orientado al logro de mayores niveles de competitividad en el contexto global, donde se hace evidente el papel protagónico que deben asumir los profesionales de la contaduría pública, quienes deben ser competentes en su disciplina. También deben aportar significativamente mediante soluciones creativas e innovadoras para la eficiente gestión de las organizaciones, con conciencia y conocimiento de las necesidades y particularidades regionales, con proyección y visión global, comprometidos con su aporte al cuidado del medio ambiente y ratificando su esencia como garantes de la confianza pública.

De acuerdo con la dinámica de desarrollo empresarial, en el país las microempresas representan el 92,1\% del total del tejido empresarial, mientras las pequeñas y medianas empresas el 7,4 \%. En este grupo de empresas, que representa el $99,5 \%$ del tejido empresarial del país, se ubican las empresas con niveles de supervivencia del $29,7 \%$, lo que implica que el $70 \%$ de los emprendimientos, que generalmente se clasifican como microempresas, fracasan en los primeros cinco años de su existencia.

Esta situación permite apreciar la necesidad en la formación de profesionales de la contaduría pública, competentes, con formación integral para apoyar el crecimiento y permanencia de este gran tejido empresarial que lo necesita y que contribuirá significativamente al fortalecimiento organizacional y al desarrollo económico y social del país.

Al consultar a empresarios del país, resaltaron como elementos fundamentales a ser considerados para orientar la formación del futuro profesional de la contaduría pública, los siguientes aspectos:

- Aportar al desarrollo del sector empresarial de manera ética, competente, organizada, transparente y socialmente responsable. 
- La actualización permanente del saber propio de su profesión, tanto en el ámbito local como global, con amplio dominio de los estándares internacionales de información financiera y de aseguramiento de la información.

- Capacidad para aportar activamente en la gestión de las organizaciones, actuar en multicontextos sociales, culturales y organizacionales, en los actuales contextos competitivos y globalizados en que se desarrolla el tejido empresarial

- Capacidad para investigar científicamente los problemas que impactan las organizaciones desde la disciplina del contador, para que aporte con soluciones creativas e innovadoras en la gestión de las organizaciones.

Los análisis realizados conducen a determinar las necesidades del sector empresarial que demanda contadores públicos competentes en la disciplina, que respondan a las necesidades de las empresas desde las diferentes regiones del país y en los diferentes sectores económicos donde intervienen, con visión de los retos que enfrenta el sector empresarial en el actual contexto globalizado en que se desarrolla, con formación integral que aporte significativamente en la gestión de empresas sostenibles y conscientes de la función social implícita en tanto generadores de la confianza pública. Aporte significativo considerando el actual momento de posconflicto que vive Colombia y que demanda el impacto regional con educación de calidad.

\section{Referencias}

Confecámaras. Confederación Colombiana de Cámaras de Comercio. (s.f.). Recuperado de: http://www.confecamaras.org.co

Confecámaras. Confederación Colombiana de Cámaras de Comercio. (2016).

Nacimiento y superviencia de las empresas en Colombia. Recuperado de: http:// www.confecamaras.org.co/phocadownload/Cuadernos_de_analisis_economico/ Cuaderno_de_Analisis_Economico_N_11.pdf 
Confecámaras. Confederación Colombiana de Cámaras de Comercio. (2017). Informe de gestión 2016-2016. Recuperado de: http://www.confecamaras.org.co/ documentos?download=16:informe-de-gestion-septiembre-2015-2016

Junta Central de Contadores. (2017). Organización de la UAE JCC. Recuperado de: http://www.jcc.gov.co/jcc/organizacion/organizacion-de-la-uae

Junta Central de Contadores. (2017). Sanciones a contadores públicos. Recuperado de: http://sgr.jcc.gov.co:8080/apex/f?p=119:1:0:.:.::

Junta Central de Contadores. (2017). Estadísticas contadores públicos. Recuperado de: https:// docs.google.com/spreadsheets/d/1d5uj_Aho2bdiOwHYFp8ZgErogljGOI2uMOlfurk7Rwl/ edit\#gid=10516143

Ministerio de Comercio, Industria y Turismo. (2017). Acuerdos vigentes. Recuperado de: http://www.tlc.gov.co/publicaciones/5398/acuerdos_vigentes

Observatorio Laboral para la Educación. (2017). Caracterización de graduados. Recuperado de: http://bi.mineducacion.gov.co:8380/eportal/web/men-observatoriolaboral/ubicacion-geografica

Sociedad de Agricultores de Colombia. (2017). Estudios económicos. Recuperado de: https://www.sac.org.co/es/estudios-economicos.html

Universidad Nacional Abierta y a Distancia (UNAD). (2016). Estudio de percepción de los empresarios del país respecto del desempeño profesional de la contaduría pública. Escuela de Ciencias Administrativas, Contables, Económicas y de Negocios. Bogotá, Colombia 